\title{
The New Zealand Rugby Injury and Performance Project: I. Design and methodology of a prospective follow-up study
}

\author{
Anna E. Waller ScD*, Michael Feehan Dip CIPs PhD ${ }^{\dagger}$, Stephen W. Marshall BSc, DipAgSci* \\ and David J. Chalmers PhD* \\ *Injury Prevention Research Unit, University of Otago, Dunedin, New Zealand, and ${ }^{\dagger}$ Prevention Research \\ Center, Department of Mental Hygiene, The Johns Hopkins School of Public Health, Baltimore, USA
}

Injury resulting from participation in sporting and physical recreational activities is a major contributor to the overall incidence of injury in the developed world. If sports injuries are to be reduced, a comprehensive approach must be taken to define the nature and magnitude of the problem, to establish models of relationships between risk factors, protective factors and injury experience, and to address injury through well designed intervention and evaluation programmes. The Rugby Injury and Performance Project (RIPP) is a prospective cohort study designed to examine the risk and protective factors for rugby injury. Data were collected on potential risk and protective factors from the RIPP cohort pre-season. Data on exposure to rugby, injury events and medical treatments were collected from the players each week during the season through telephone interviews. Pre-season measures were repeated post-season. A key feature of the design was that data were collected on both injured and non-injured players, allowing a longitudinal comparison of the injury experience of players with and without the factors of interest. A wealth of information was collected on each cohort member during the preseason interview. A contact rate of $90 \%$ was achieved during the weekly follow-up phase. Post-season questionnaires were completed by $76 \%$ of the players and $88 \%$ of the coaches. Recommendations are made for the use of this methodology by other researchers and future directions for RIPP are described.

Keywords: Rugby, epidemiology

Injury resulting from participating in sporting and physical recreational activities is a major contributor to the overall incidence of injury in the developed world. A 1-year study of a Swedish community found that $17 \%$ of all medically treated injuries were sports-related (excluding cycling and walking) ${ }^{1}$. In New Zealand, a country of 3.3 million people, it is clear from the national no-fault injury compensation scheme statistics that sports injury is a major problem. The Accident Rehabilitation and Compen-

Address for correspondence: Anna E. Waller, Injury Prevention Research Unit, University of Otago, Department of Preventive and Social Medicine, PO Box 913, Dunedin, New Zealand.

(C) 1994 Butterworth-Heinemann Ltd

0306-3674/94/040223-06

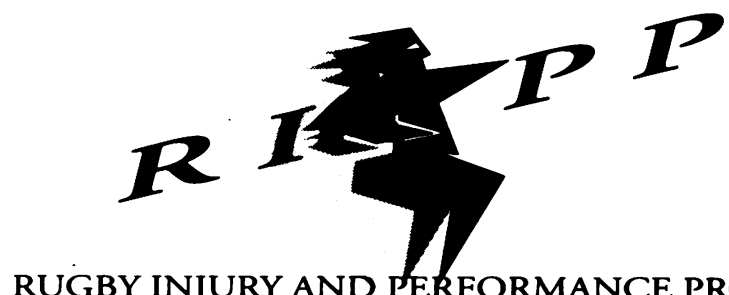

RUGBY INJURY AND PERFORMANCE PROJECT

sation Insurance Corporation (ACC) provided compensation for over 38500 claims ( $16 \%$ of all claims) for sporting injuries during the 1992 financial year, at a cost of almost NZ $\$ 98$ million dollars ${ }^{2}$.

The Life in New Zealand study, a population-based survey of lifestyles, estimated that the average New Zealander spends approximately 21 hours per week on physical activities ${ }^{3}$. The New Zealand Hillary Commission for sport, fitness and leisure states that the only negative consequence of a physically active lifestyle is the risk of injury ${ }^{4}$. With the promotion of physical fitness as a preventive measure for many illnesses, the incidence of sports-related injury is likely to increase over time. Given that most people participate in sports for fun and physical fitness, efforts should be made to reduce the injury toll of this leisure activity.

If sports injuries are to be reduced, a comprehensive approach must be taken to define the nature and magnitude of the problem, establish models of relationship between risk factors, protective factors, and injury experience, and address injury through well designed intervention and evaluation programmes $^{5}$. Although there is an abundance of literature on sports injuries, most studies have focused on the physical damage and its treatment. Little has been reported about risk factors and protective factors for these injuries. Most studies have used a case-series methodology and few have been population-based. Fewer still have utilized an analytical methodology from which conclusions may be drawn about risk factors for injury. This lack of analytical research has been acknowledged and calls have been made for the application of analytical epidemiologic methods to sports injury ${ }^{6-8}$. Nevertheless, progress in this direction has so far been limited. 
The recommended analytical method for this type of research is the prospective cohort design. This design 'is generally regarded as the strongest of the comparative designs, from the methodological point of view. It greatest strength lies in the fact that the risk profile for each study subject is established before the outcome is observed'7. This type of research has not been forthcoming probably because of time and financial constraints ${ }^{7,9}$. Although analytical studies can be complex, they are needed in order to develop comprehensive models of sports injury. The study of sports injury lends itself particularly well to the use of the prospective cohort methodology. Unlike many other health outcomes, sport injuries are not rare events: in fact they are relatively common in many sports. Following a cohort of athletes for one season or a few months is usually adequate for data collection. The successful application of this method to the study of both child and adult athletes has been demonstrated $^{10,11}$.

In New Zealand, rugby union is the logical place to start the study of risk and protective factors for sports injury. It is a sport with high rates of both participation and injury. If is also a sport of national prominence and importance. The numbers who play the sport have been variously estimated between 125000 and $210000^{3,12}$. Rugby union has the highest rate of injury of all major sports in New Zealand ${ }^{13}$. Because of the high injury rate and the large number of players, rugby union contributes the largest total number of injuries of any sport that result in ACC claims, Accident and Emergency visits, and hospitalizations in New Zealand ${ }^{14,15}$.

It has been suggested that many rugby injuries are preventable $^{16}$. Most previous studies, however, have looked only at factors associated with those rugby players who sustain an injury. Uninjured players were not examined and may have possessed the same or different factors as their injured counterparts.

The Rugby Injury and Performance Project (RIPP) is a prospective cohort study designed to examine the risk and protective factors for rugby injury. The major aims of this project are:

1. To develop a model of sports injury through the identification of risk and protective factors for injury experienced by rugby union players;

2. To develop and test a methodology for studying sports injury that will be readily adaptable to different sports and other levels of play;

3. To design and pilot components of an injury prevention programme, including evaluation, based on the results of the cohort study.

RIPP is a collaborative effort between the Injury Prevention Research Unit and the School of Physical Education at the University of Otago in Dunedin, New Zealand. The research team includes injury epidemiologists, biomechanists, sports medicine specialists, clinical and sports psychologists and exercise prescription experts. In addition, the local and national rugby football unions have been consulted about RIPP since its inception.

This paper describes the design and methods used in RIPP. The Results section presents the successes and failures of using these methods to collect the information necessary to develop a model of sports injury. Additional papers in this journal and in the future will describe the results of analyses using the RIPP database.

\section{Methods}

Players were recruited to participate in RIPP through their clubs and team coaches during the pre-season training period before the start of the 1993 season. Players from five clubs and four secondary schools were invited to participate if they planned to play in one of the following grades during the 1993 season: senior A, senior women, senior B, under 21, schoolboys or schoolgirls. Incentives, such as feedback about physical fitness performance measures, tee-shirts and water bottles were used to encourage the participation of the players, the coaches and the teams. The local rugby football union was consulted to identify grades to include, clubs and schools to invite to participate, coaches to contact and appropriate incentives to use.

A summary of the potential risk and protective factors measured at each phase of the study is presented in Table 1. Wherever possible, published measures were used to allow both New Zealand and overseas comparisons to be drawn.

The phases of data collection are illustrated in Figure 1. Data were collected on potential risk and protective factors from the cohort during pre-season. Data on exposure to rugby and potential risk and protective factors, injury events and medical treatments were collected from the players each week through telephone interviews during the season. Many of the pre-season measures were repeated post-season. This research method allows a longitudinal comparison of the injury experience of players with and without the factors of interest.

Pre-season data were collected when the players attended an assessment evening. Participants completed a consent form followed by a self-administered questionnaire. After completing the questionnaire, players were given a physical assessment that included anthropometric measurements and various physical fitness measures designed to relate to specific aspects of rugby fitness. The entire session lasted approximately $2^{1 / 2}$ hours.

Following their enrolment in the study, each participant was assigned to a trained telephone interviewer who rang the player each week to conduct a brief interview about his or her rugby exposure and injury experience in the past week. Additional details were collected about any event that resulted in an injury requiring medical attention or causing the player to miss at least one scheduled game or team practice. Players were followed throughout their season (club and/or representative) with the weekly telephone interviews and were never asked to recall more than one week's worth of information. Each interviewer called the same players each week in order to facilitate interviewer-player rapport. Telephone interviewers were trained using simulated interview situations and followed a set 
protocol. Special protocols were developed for handling unusual, difficult and traumatic situations.

At the end of the regular club season, the pre-season questionnaire and physical assessment measures were repeated. Players were again asked to

Table 1. Potential risk and protective factors by data collection phase (RIPP cohort, 1993)

\begin{tabular}{|c|c|c|c|}
\hline \multirow[t]{2}{*}{ Potential factors } & \multicolumn{3}{|c|}{ Data collection phase } \\
\hline & Pre-season & Weekly & Post-season \\
\hline \multicolumn{4}{|l|}{ Demographics } \\
\hline Gender & $\sqrt{ }$ & & $\sqrt{ }$ \\
\hline Age & $\sqrt{ }$ & & $\sqrt{ }$ \\
\hline Ethnicity & $\sqrt{ }$ & & \\
\hline Education & $\sqrt{ }$ & & \\
\hline Occupation & $\sqrt{ }$ & & $\sqrt{ }$ \\
\hline Income & $\sqrt{ }$ & & \\
\hline \multicolumn{4}{|l|}{ Rugby experience/exposure } \\
\hline Consecutive years played & $\sqrt{ }$ & & \\
\hline Grade & $\sqrt{ }$ & $\sqrt{ }$ & $\sqrt{ }$ \\
\hline Position & $\sqrt{ }$ & $\sqrt{ }$ & $\sqrt{ }$ \\
\hline Type of competition & $\sqrt{ }$ & $\sqrt{ }$ & $\sqrt{ }$ \\
\hline $\begin{array}{l}\text { Number of games/team } \\
\text { practices }\end{array}$ & & $\sqrt{ }$ & \\
\hline Foul play involvement & & $\sqrt{ }$ & $\sqrt{ }$ \\
\hline \multicolumn{4}{|l|}{ Anthropometry } \\
\hline Height & $\sqrt{ }$ & & $\sqrt{ }$ \\
\hline Weight & $\sqrt{ }$ & & $\sqrt{ }$ \\
\hline Body mass index & $\sqrt{ }$ & & $\sqrt{ }$ \\
\hline Somatotype & $\sqrt{ }$ & & $\sqrt{ }$ \\
\hline \multicolumn{4}{|l|}{ Physical fitness } \\
\hline Aerobic fitness & $\sqrt{ }$ & & $\sqrt{ }$ \\
\hline Anaerobic endurance & $\sqrt{ }$ & & $\sqrt{ }$ \\
\hline Agility & $\sqrt{ }$ & & $\sqrt{ }$ \\
\hline Speed/acceleration & $\sqrt{ }$ & & $\sqrt{ }$ \\
\hline Upper body strength & $\sqrt{ }$ & & $\sqrt{ }$ \\
\hline Vertical jump height & $\sqrt{ }$ & & $\sqrt{ }$ \\
\hline \multicolumn{4}{|l|}{ Injury experience } \\
\hline Past & $\sqrt{ }$ & & $\sqrt{ }$ \\
\hline Current & $\sqrt{ }$ & $\sqrt{ }$ & $\sqrt{ }$ \\
\hline Chronic & $\sqrt{ }$ & $\sqrt{ }$ & \\
\hline \multicolumn{4}{|l|}{ Training/preparation } \\
\hline Off-season & $\sqrt{ }$ & & \\
\hline During season & & & $\checkmark$ \\
\hline Warm-ups/warm-downs & $\checkmark$ & $\sqrt{ }$ & $\checkmark$ \\
\hline $\begin{array}{l}\text { Use of protective } \\
\text { equipment }\end{array}$ & $\sqrt{ }$ & $\sqrt{ }$ & $\sqrt{ }$ \\
\hline \multicolumn{4}{|l|}{ Sports psychology } \\
\hline Competition anxiety & $\sqrt{ }$ & $\sqrt{ }$ & $\sqrt{ }$ \\
\hline Goal orientation & $\sqrt{ }$ & & \\
\hline Motivations for play & $\sqrt{ }$ & & \\
\hline $\begin{array}{l}\text { Perceived competence/ } \\
\text { ability }\end{array}$ & $\sqrt{ }$ & & $\checkmark$ \\
\hline $\begin{array}{l}\text { Self-concept/self-esteem } \\
\text { of physical ability }\end{array}$ & $\checkmark$ & & \\
\hline Performance ratings & & $\sqrt{ }$ & $\sqrt{ }$ \\
\hline Attitudes towards rugby & $\sqrt{ }$ & & $\sqrt{ }$ \\
\hline $\begin{array}{l}\text { Use of psychological } \\
\text { skills training }\end{array}$ & $\sqrt{ }$ & & $\sqrt{ }$ \\
\hline \multicolumn{4}{|l|}{ General health and well-being } \\
\hline Acute/chronic illness & $\sqrt{ }$ & $\sqrt{ }$ & \\
\hline Worries about health & $\sqrt{ }$ & & $\sqrt{ }$ \\
\hline Sleep disturbance & $\sqrt{ }$ & $\sqrt{ }$ & $\sqrt{ }$ \\
\hline Tobacco use & $\sqrt{ }$ & & $\sqrt{ }$ \\
\hline Alcohol use & $\sqrt{ }$ & $\sqrt{ }$ & $\sqrt{ }$ \\
\hline Other drug use & $\sqrt{ }$ & & $\sqrt{ }$ \\
\hline Positive/negative affect & $\sqrt{ }$ & & $\sqrt{ }$ \\
\hline Depressive symptoms & $\sqrt{ }$ & & $\sqrt{ }$ \\
\hline Social support & $\sqrt{ }$ & & $\sqrt{ }$ \\
\hline Anger expression & $\sqrt{ }$ & & $\sqrt{ }$ \\
\hline Stressful life events & $\sqrt{ }$ & $\sqrt{ }$ & $\sqrt{ }$ \\
\hline
\end{tabular}

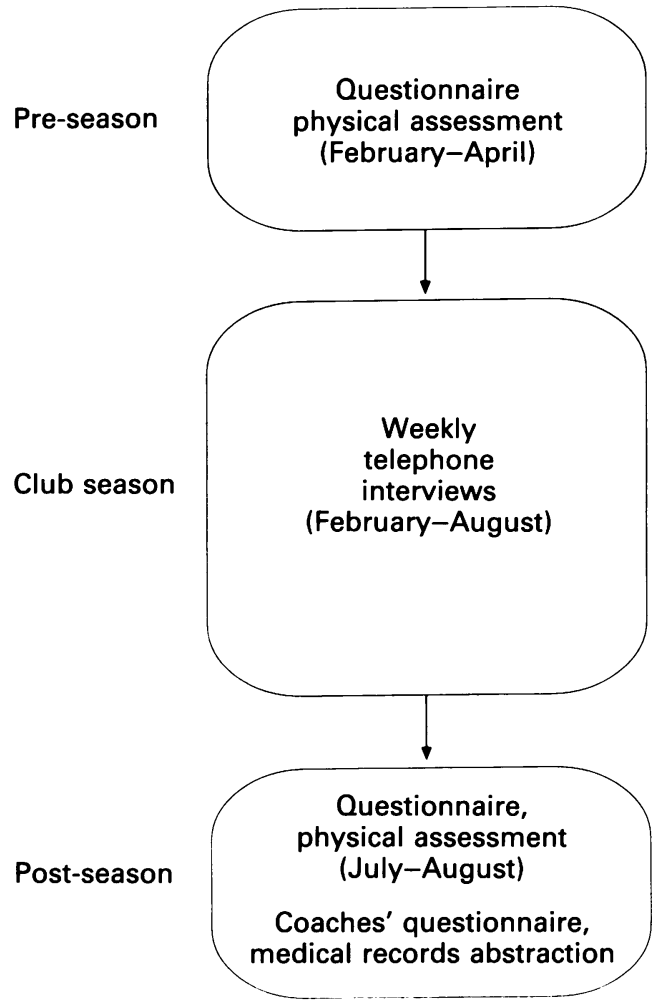

Figure 1. Data collection phases (RIPP cohort, 1993)

attend an assessment evening to complete the physical assessment. Most players were mailed the post-season questionnaire with a stamped return envelope, although some players completed it during the assessment session.

Information complementary to that collected from the players at the end of the season was collected from coaches in the Dunedin area by means of a self-administered questionnaire mailed to them with a stamped return envelope. Additional information relating to the diagnosis and treatment of medically attended injuries was abstracted from the medical records after the end of the rugby season.

\section{Results}

All the clubs and schools invited to participate in RIPP agreed to do so. All but two of the 25 teams eligible to participate through their club or school also did so. No team refused to participate, but two were unable to attend an assessment evening due to scheduling conflicts. At the time of the pre-season assessments, team members were still being selected so team constitution was somewhat fluid and players were sometimes uncertain about what grade they would eventually play during the seaon. A total of 356 players were enrolled in the cohort. Of these, 350 completed the pre-season questionnaire, 349 completed the pre-season physical assessment, and 344 players completed both. With the exception of the schoolgirl teams, most members of participating teams were enrolled in the study cohort. Because 1993 was the first ever season of schoolgirl rugby in 


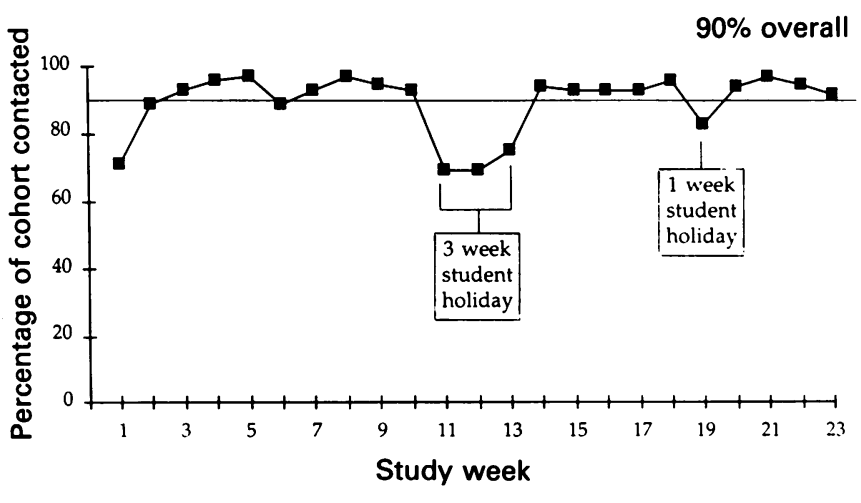

Figure 2. Weekly contact during the regular club season (RIPP cohort, 1993)

Dunedin, team organization and recruitment of players were somewhat less efficient than in other teams.

No weekly interviews were conducted with three players $(<1 \%)$ who lived in households with no telephone and could not be contacted by telephone at work or school. Another four players were not followed during the season for various other reasons, e.g. because they lived or worked out of town or provided incomplete consent. Thus a total of 349 players ( $98 \%$ of the cohort) were followed weekly during the regular club rugby season. The seven players not followed during the weekly phase were included in the post-season assessments.

Overall, during the 23 weeks of regular club season follow-up, the telephone interviewers were able to complete $90 \%$ of the interviews they attempted, as shown in Figure 2. In most weeks, telephone interviews were completed with $90-95 \%$ of the players. There are two noticeable dips in the graph, both coinciding with student holidays. Many RIPP participants $(69 \%)$ were enrolled in secondary or tertiary education and many of these players were absent from Dunedin during weeks 11-13 (May holidays) and week 19 (midwinter break). Data on 5810 player-weeks of information were collected during the regular club season, including details of 663 injury events and over 4200 player-games. The length of the weekly telephone interviews varied depending on the number of games played and the number of injury events experienced during the week. The mean interview length was $4.7 \mathrm{~min}$ and $86 \%$ of the interviews took $6 \mathrm{~min}$ or less to complete.

Over the weekly data collection phase, six players withdrew from the study: four because they were leaving Dunedin and two for personal reasons. Neither of those who withdrew for personal reasons had played any rugby games during the season. Six players in the cohort played no rugby games during the season, four due to injury or re-injury during the pre-season training period.

Only 100 participants $(29 \%)$ were able to be retested on the physical assessment measures at the end of the season. As a result of the poor attendance at the scheduled assessment evenings, the postseason questionnaire, with a stamped return envelope, was mailed out to all participants after the club season concluded. Of the 350 cohort members still participating at the end of the club season, 267 returned completed questionnaires, a $76 \%$ response rate.

The coaches' questionnaire was mailed to all 48 Dunedin area coaches of club teams in the grades enrolled in RIPP as well as schoolboy and schoolgirl coaches at all Dunedin area secondary schools. Forty-two completed questionnaires (88\%) were returned.

\section{Discussion}

The methodology presented in this paper has proven very successful for studying injury and performance factors among rugby players. Methods used in other population-based studies of rugby injury have often proved problematic. A study of schoolboy rugby injuries in South Africa found that personal follow-up with players almost doubled the reported injury rate compared to mailed survey responses ${ }^{17}$ and concluded that the 'most accurate method of data collection is direct personal contact between the researcher and the injured player'. A New Zealand study that utilized a pyramid approach to data collection concluded that 'only a portion of the actual number of injuries was recorded"9, and recommended that professional data collectors be used to follow a small cohort of players. Our methodology incorporated both of these recommendations.

By interviewing every player in the cohort each week, regardless of injury status, this study provides a wealth of information about the experience of playing rugby and the impact of injury on that experience. It was necessary, however, to achieve a high follow-up rate during the interviewing phase to ensure our data were free of systematic error and were considered valid. Despite initial concerns about the intrusiveness of a weekly telephone call, less than $2 \%$ of the cohort actually withdrew from the study. The only study reported in the literature that used similar follow-up methods (i.e. weekly telephone interviews) achieved a similar contact rate (89\%) over 12 weeks of follow-up with adult fitness club members ${ }^{11}$. We suspected that our rugby-playing cohort might prove somewhat more difficult to follow on a regular basis than adult fitness club members due to their generally younger ages, the high proportion of students and their often unsettled lifestyle, but this was not the case. Our $90 \%$ contact rate has shown the methodology to be successful with two very different populations and indicates that it is appropriate for use with a wide range of sporting populations.

If the weekly telephone follow-up was the major strength of the RIPP methodology, the post-season physical assessments were the major weakness. A variety of factors contributed to the low response rate including the number of players who were carrying an injury at the end of the season and the fact that the beginning of the second major holiday period of the academic year coincided with the end of the club rugby season. Although we went to great lengths to encourage the cohort members to attend the postseason assessment sessions, players who were injured, on holiday or exhausted after the rugby 
season were unlikely to return for a second physical assessment. Another factor which may have influenced the poor post-season response was the difficulty of the physical assessment which was designed to push players to their maximum performance level on measures of a variety of fitness components. While some people respond to the physical and mental challenge of such tests, many do not and find the experience unpleasant. The opportunity to repeat the assessment at the end of the season and compare results to pre-season performance was seen as an incentive by the researchers but experience proved that it was not seen this way by many players, particularly those who performed poorly at preseason. The response to the mailed out post-season questionnaire was encouraging, however, given that this was not the intended method of administration.

The rugby players, coaches and administrators proved to be extremely enthusiastic about participating in RIPP. The very high contact rate for weekly interviews during the season is a tribute to the dedication of the players to this endeavour to improve the game and to the skills and tenacity of our telephone interviews. This project would never have been possible without the full cooperation and support of the local and national rugby football unions. Any project planning to use intensive data-collection techniques such as those used in RIPP should involve the administrators of the sport in the development of the project from the very beginning. Coaches and players should also be consulted when designing the study. The use of incentivies in this project worked to encourage both initial participation and ongoing cooperation from the players. The incentive programme used was minimal and better compliance with the post-season assessments may have been attained with more and/or better incentivies.

One of the biggest problems faced by this project was the lack of sufficient time between the funding award and the commencement of data collection. With only two months' notice, it was very difficult to find a venue for the physical asessments. Facilities with the necessary space and equipment were limited and already heavily booked for the entire year. When

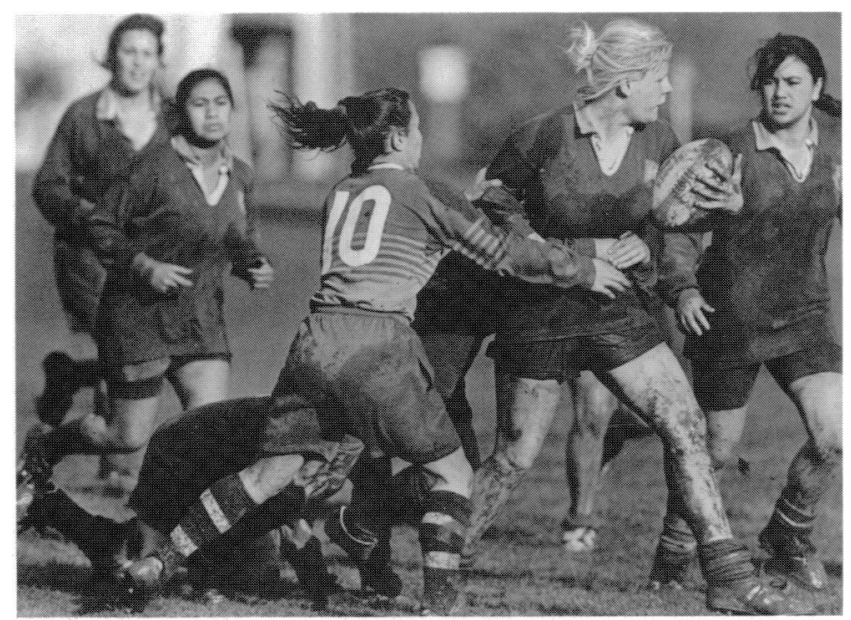

Figure 3. Women's rugby has become part of the New Zealand scene. (Courtesy of Otago Daily Times)

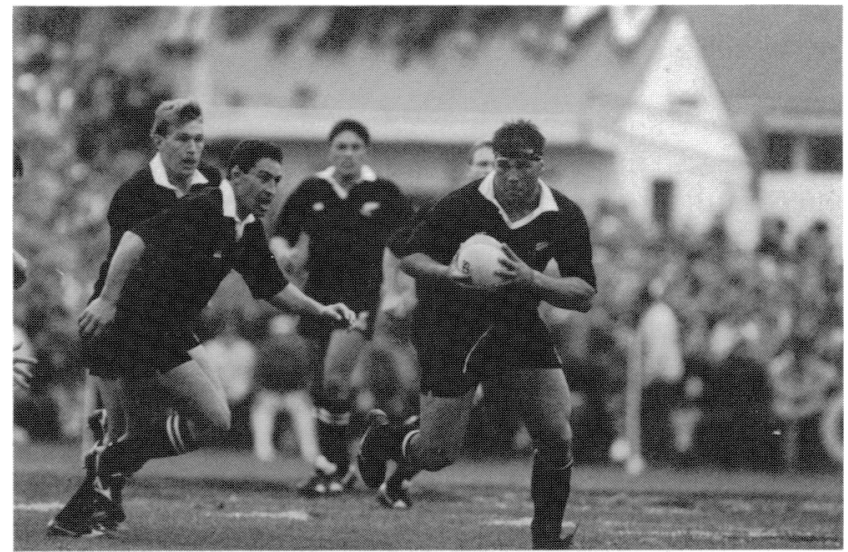

Figure 4. The All Blacks have contributed to making rugby a sport of national prominence and importance. (Courtesy of Otago Daily Times)

planning such a project, we would recommend booking facilities for assessments at least a year in advance. Having appropriate venues available at times that cause the least disruption to the players' and teams' schedules is a key factor in participation and ease of administration.

The Rugby Injury and Performance Project represents an analytical epidemiological approach to the study of sports injury. As such, it is designed to provide information about a large number of rugby players and the injury events they experience. This population-based approach limits the detail available about the specific clinical outcomes or biomechanical influences on individual injuries, and therefore cannot answer every question of interest to those concerned with preventing rugby injury. The choice of a study population was very important because we want to be able to generalize our results to other rugby players. Practical considerations are also important, however, when choosing a cohort to study. Thus, the RIPP cohort was selected partly to provide the range of grades and experience levels we wished to investigate and partly to facilitate followup.

We know that some players did not attend the pre-season assessments because they were already injured and felt unable to perform well on the physical fitness tests. Many players who did enrol in the cohort reported current and/or chronic injuries that affected their ability to train for and play rugby. Current, chronic and previous injury are all considered potential risk factors for further injury in this study. A complication of conducting analytical epidemiological studies of sportspersons is that they continue to play or return to their sport after suffering injury. In most prospective cohort studies, an individual who acquires the outcome of interest (e.g. lung cancer) would cease to contribute to the follow-up data. The high incidence of injury in the rugby-playing population coupled with the fact that many players will continue to play once injured, introduces additional levels of complexity into the analysis and interpretation of the data.

An advisory panel comprising representatives of the local and national rugby unions, players, coaches 
and referees has been established and is working with the RIPP research team to use the findings of this project to develop strategies for injury prevention in rugby in New Zealand. The methods developed and used in RIPP have proven very successful and we would encourage others interested in examining risk and protective factors for sports injury to consider using such a methodology.

\section{Conclusion}

The project described here is one of the most comprehensive studies of sports injury undertaken to date. It provides a unique opportunity to study rugby injury, its antecedents and the roles and relationship between these factors. The team of researchers assembled for this project bring complementary skills and expertise which serve to enhance the multidisciplinary nature of the research. The interest, enthusiasm and cooperation of both the local and national rugby football unions has been essential to the success of the project. Their continued support will be imperative for the successful implementation of the intervention programme that is developed from the results of this study.

\section{Acknowledgements}

The Rugby Injury and Performance Project is funded by a grant from the Accident Rehabilitation and Compensation Insurance Corporation. The Injury Prevention Research Unit is jointly funded by the Health Research Council of New Zealand and the Accident Rehabilitation and Compensation Insurance Corporation. The views expressed in this paper are those of the authors and do not necessarily reflect those of the above organizations. The authors wish to thank the following people without whom this project would not have been possible: the RIPP cohort members; Ken Quarrie; Yvonne Bird; Martin Toomey and the staff of the Human Performance Centre; our talented telephone interviewers; Dianne Allnatt; the RIPP co-investigators; Pam Jemmett; Peter Scott; Ralph Requa and James Garrick; Ian Ansell of Coaching New Zealand; Jon Doig of the Hillary Commission; and John Langley, Director,
IPRU. We also wish to acknowlegde the support, encouragement cooperation, and invaluable advice of the Otago Rugby Football Union and the New Zealand Rugby Football Union.

\section{References}

1 de Loës M. Medical treatment and costs of sports-related injuries in a total population. Int I Sports Med 1990; 11: 66-72.

2 Accident Rehabilitation and Compensation Insurance Corporation. ACC Injury Statistics 1992. Wellington: Accident Rehabilitation and Compensation Insurance Corporation, 1992.

3 Russell D, Wilson N. Life in New Zealand. Commission Report Volume 1: Executive Overview. Wellington: Hillary Commission for Recreation and Sport, 1991.

4 Hillary Commission. The Business of Sport and Leisure: Summary Report. The Economic and Social Impact of Sport and Leisure in New Zealand. Wellington: Hillary Commission for Sport, Fitness and Leisure, 1993.

5 Lysens RJ, de Weerdt W, Nieuwboer A. Factors associated with injury proneness. Sports Med 1991; 12: 281-9.

6 Kraus JF, Conroy C. Mortality and morbidity from injuries in sports and recreation. Ann Rev Public Health 1984; 5: 163-92.

7 Walter SD, Hart LE. Application of epidemiological methodology to sports and exercise science research. Exercise and Sport Science Review 1990; 18: 417-48.

8 Meeuwisse WH. Predictability of sports injuries. What is the epidemiological evidence? Sports Med 1991; 12: 8-15.

9 Dalley DR, Laing DR, McCartin PJ. Injuries in rugby football, Christchurch 1989. NZ J Sports Med 1992; 20: 2-6.

10 Brust JD, Leonard BJ, Pheley A, Roberts WO. Children's ice hockey injuries. Am J Dis Children 1992; 146: 741-7.

11 Requa RK, DeAvilla N, Garrick JG. Injuries in recreational adult fitness activities. Am J Sports Med 1993; 21: 461-7.

12 MRL Research Group. Population injury survey. ACC Publication 105. Wellington: Accident Compensation Corporation 1987.

13 Accident Compensation Corporation. ACC Statistics - Sports Injuries 1989/90, vol. 2/91. Wellington: Accident Compensation Corporation, 1991.

14 Dixon G. Morbidity of rugby union injuries in New Zealand. NZ I Sports Med 1993; 2: 18-20.

15 Hume P, Marshall SW. Sports injuries in New Zealand: exploratory analyses. $N \mathrm{Z} J$ Sports Med, in press.

16 Egger G. Sports Injuries in Australia: causes, costs and prevention. Health Prom J Austr 1991; 1: 28-33.

17 Roux CE, Goedeke R, Visser GR, Van Zyl WA, Noakes TD. The epidemiology of schoolboy rugby injuries. SAMJ 1987; 71: 307-13. 